\title{
Interrupted versus Continuous Suture Technique for Ventricular Septal Defects Surgical Closure
}

\author{
Rafik F.B. Soliman*1, Sherif S. Salim ${ }^{2,3}$, Luna S. Baangood ${ }^{2}$, \\ Abdulhamid Alnajjar' ${ }^{2}$, Ayman R. Abdelrehim ${ }^{1,4}$ \\ ${ }^{1}$ Cardiothoracic Surgery Department, Faculty of Medicine, Menoufia University, Menoufia, Egypt \\ ${ }^{2}$ Pediatric Cardiology Department, Madina Cardiac Center, Madina, Saudi Arabia \\ ${ }^{3}$ Paediatric Department, Faculty of Medicine, Menoufia University, Menoufia, Egypt \\ ${ }^{4}$ Cardiac Surgery Department, Madina Cardiac Center, Madina, Saudi Arabia \\ *Corresponding author: Rafik F.B. Soliman, Mobile: (+20) 01011102102, E-Mail: rafikfekry@ hotmail.com
}

\begin{abstract}
Background: Ventricular septal defect (VSD) is the most frequent congenital cardiac defect. Conventionally, openheart surgical repair through cardiopulmonary bypass (CPB) is the primary approach for many years.

Objective: Given the absence of a reliable evidence on the optimal suture technique regarding the efficacy and morbidity, this study aimed to compare the postoperative complication rates and the outcomes of the interrupted and continuous suture techniques for the surgical VSD closure.

Patients and Methods: This retrospective cohort study included 140 consecutive children who underwent surgical closure of congenital VSD of any type with or without associated congenital heart diseases. Patients with associated major cardiac anomalies were excluded. Preoperative, operative, and long-term outcomes data including VSD residual and heart block that needed permanent pacemaker (PPM) were collected from medical files. The closure was performed using interrupted sutures in 76 (54.3\%, group 1), and by continuous sutures in 74 (45.7\%, group 2) patients.
\end{abstract}

Results: Three (3.9\%) patients in group 1 and four (6.3\%) patients in group 2 developed heart block that needed PPM, with no significant difference ( $\mathrm{p}=0.702)$. Four (5.3\%) patients in group 1 compared with two (3.1\%) patients in group 2 had clinically and sizable (by echocardiography) significant residual, with no significant differences between both groups $(\mathrm{p}=0.688$ ).

Conclusion: The present study indicates that interrupted and continuous VSD closure techniques have comparable success and postoperative complication rates. Thus, the optimal suturing technique for VSD closure cannot be standardized, and their predilection depends on the experience and the comfort of the surgeons.

Keywords: Heart block, Residual VSD, Surgical closure, Ventricular septal defect.

\section{INTRODUCTION}

Ventricular septal defect (VSD) is the most frequent congenital cardiac defect. It commonly occurs as isolated defect in the interventricular septum, and it also constitutes a fundamental part of complex congenital cardiovascular anomalies ${ }^{(1)}$. The incidence of VSD is 1.75-4.48 per million live births, while the incidence of isolated VSD is about $0.3 \%$ of newborns (2).

Diagnosis of VSD is mainly by echocardiography, which plays a major role in detecting the VSD, the individual anatomy of the case, and the associated anomalies or complications ${ }^{(3)}$. The VSD defect commonly (80\%) shrink and closes spontaneously within the first month of life (4), especially the isolated defects ${ }^{(5)}$. If not closed, large defects can lead to unfavorable complications such as pulmonary arterial hypertension, ventricular dysfunction, with an increased risk of arrhythmias. In this case, surgical repair is the ultimate treatment ${ }^{\left({ }^{6}\right)}$.

Conventionally, open-heart surgical repair through midline sternotomy and cardiopulmonary bypass $(\mathrm{CPB})$ is the primary approach for many years (7). Surgical VSD closure commonly performed through the right atrial approach in which the VSD is reached through the tricuspid valve ${ }^{(8)}$. The interventricular septum is typically closed by using an autologous pericardium patch, which is fixed by either interrupted or continuous suturing techniques depending on the surgeon preference ${ }^{(9)}$. However, there may be differences in the postoperative outcomes and complications of the two techniques.

Given the absence of a reliable evidence on the optimal suture technique regarding the efficacy, and morbidity, this study aimed to compare the postoperative complication rates, and the outcomes of the interrupted and continuous suture techniques for the surgical VSD closure.

\section{PATIENTS AND METHODS}

This retrospective cohort study was conducted at the Department of Pediatric Cardiac Surgery, Madina Cardiac Center, KSA and El Aml Hospital, Egypt.

\section{Ethical approval:}

The study was conducted according to the World Medical Association Declaration of Helsinki, after the approval of the Research Ethics Committee, Madina 
Cardiac Center, KSA and El Aml Hospital, Egypt. The confidentiality of patients' data was preserved by using a coding system for every patient.

\section{Inclusion criteria:}

140 consecutive children who underwent surgical closure of congenital VSD of any type, patients with multiple VSD, or VSD associated with atrial septal defect, coarctation of the aorta, patent ductus arteriosus (PDA), pulmonary artery hypertension, pulmonary artery stenosis and/or previous pulmonary artery banding $(\mathrm{PAB})$ were included. Patients were divided into two groups according to the surgical technique: Group1 (interrupted) and group 2 (continuous) sutures techniques.

\section{Exclusion Criteria:}

Patients had associated major cardiac anomalies such as discordant atrioventricular or ventriculoarterial connection, tetralogy of Fallot, double outlet right ventricle, or VSD with pulmonary atresia, and those with previous VSD closure surgery were excluded from the study.

\section{Data collection:}

Data of patients presenting between the $1^{\text {st }}$ of January 2014 and the end of April 2020 were collected from the hospital patients' records. Preoperative data included gender, age, and weight at the operation time, history of Down syndrome, whether there was pulmonary artery banding or not, and the pressure gradient around the band as well as the time between banding and the surgical VSD closure.

The presence of right ventricular hypertrophy, or other concomitant congenital cardiac anomalies. Operative data included the technique of surgical VSD closure, type of patch used, cross clamp and cardiopulmonary bypass (CPB) times, and the presence of intraoperative 2-3 $\mathrm{mm}$ significant residual and its size. Data during the period of intensive care unit (ICU) admission comprising the length of stay, the duration of inotropes and mechanical ventilation, the presence of heart block and the need for permanent pacing. The long-term outcomes including presence of clinically and sizable significant residual, and the need for second operation catheter or surgical VSD closure or permanent pacemaker insertion.

\section{Surgical procedures:}

In all patients, surgical procedures were accomplished through median sternotomy under CPB with cannulation of both the superior-inferior vena cava and mild-to-moderate systemic hypothermia. Intermittent cold blood cardioplegia was used for myocardial preservation. None of the cases required total circulatory arrest. The VSD was accessed through right atriotomy, then the location and borders of VSD were examined to decide whether to perform patch closure of VSD in interrupted or continuous fashion according to the surgeon preference.

In the interrupted technique, the VSDs were closed with interrupted sutures all around. In continuous suturing, the patch closure of VSD was accomplished through continuous suturing all around the VSD, with shallow suturing at the posteroinferior rim of the VSD. In patients with pulmonary artery stenosis, pulmonary artery reconstructions were performed or previous $\mathrm{PAB}$, debanding of the pulmonary artery was done while the aortic crossclamp was in situ. The tricuspid valve regurgitation was tested by filling the right ventricle with saline before closure of the right atriotomy, and no patients required any intervention to the tricuspid valve. For detection of residual VSD, transesophageal echocardiography was done for patients weighing more than $5 \mathrm{~kg}$. Instead, transepicardial echocardiography was done in patients weighing less than $5 \mathrm{~kg}$ to avoid esophageal damage. In patients with concomitant PDA, it was ligated after starting CPB and before clamping the aorta. No patients needed further interventions after ending the CPB.

\section{Statistical analysis}

Statistical analysis was conducted using SPSS (Statistical Package for the Social Sciences) computer program, version 22. Categorical data were represented as numbers and frequencies.

A Chi-Square test or Fishers' Exact Test as appropriate were performed to investigate the association between the categorical variables. For continuous data, they were tested for normality by the Shapiro-Wilk test. Normally distributed data were expressed as mean \pm SD and were analyzed by the independent T-test. On the other hand, not normally distributed data were presented as median and range, and Mann-Whitney U test was applied. P-value less than 0.05 was considered statistically significant.

\section{RESULTS}

This study included 140 patients who underwent surgical closure of VSD. The closure was performed using interrupted sutures in $76(54.3 \%$, group 1$)$, and by continuous sutures in 74 (45.7\%, group 2$)$ patients. The demographic and preoperative characteristics of the studied patients are shown in table 1.

As the regard the types of VSD, there was significant difference between both groups. 
Table (1): Demographic and preoperative characteristics of the studied patients

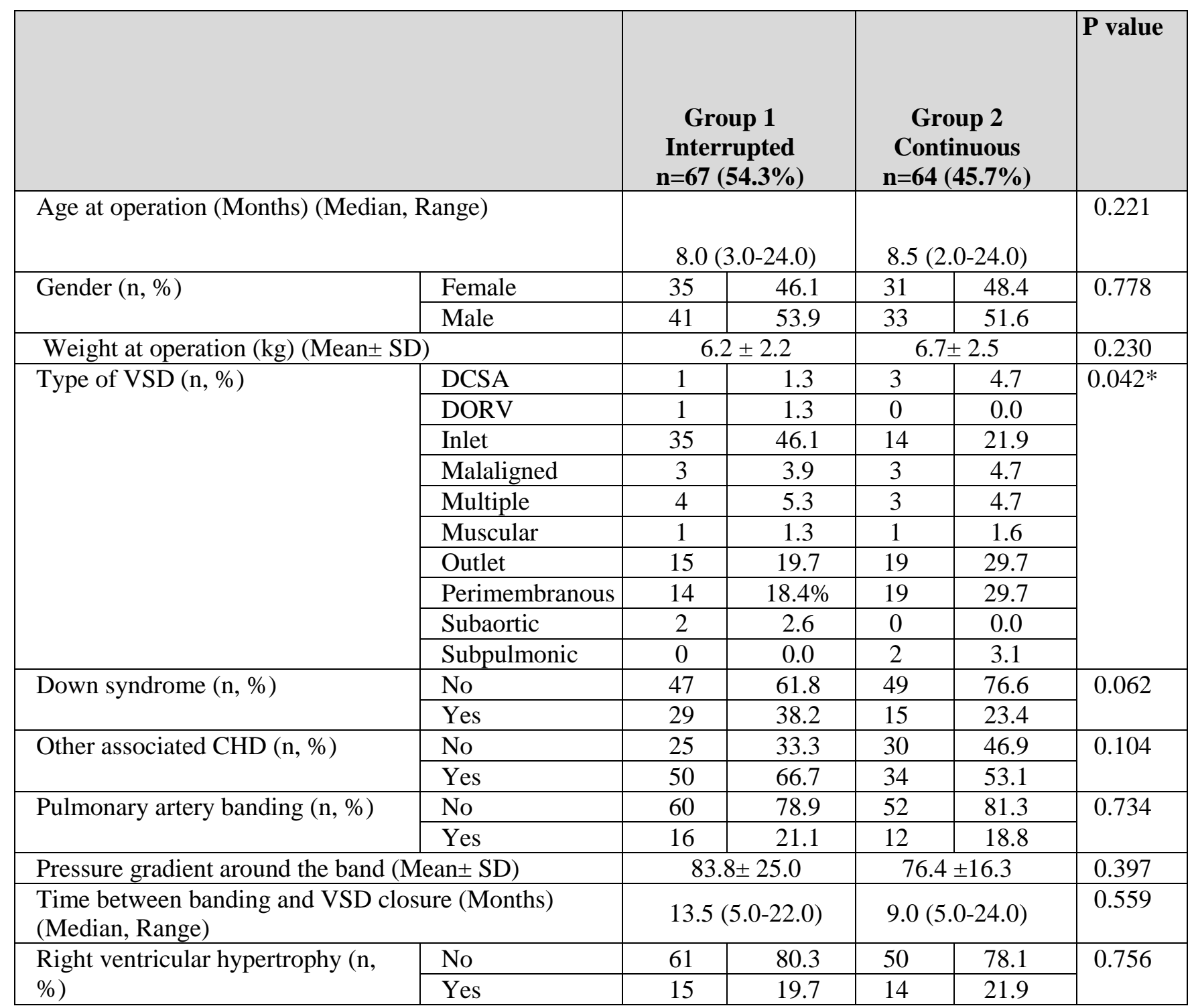

VSD: ventricular septal defect; CHD: congenital heart disease; DCSA: double committed subaortic; DORV: double outlet right ventricle; *significant at $\mathrm{p}<0.05$

Operative characteristics of the studied patients are shown in table 2. There was no significant difference between both groups.

Table (2): Operative characteristics of the studied patients

\begin{tabular}{|c|c|c|c|c|c|c|}
\hline & & & $\begin{array}{l}\text { Ip } 1 \\
\text { upted } \\
4.3 \% \text { ) }\end{array}$ & & $\begin{array}{l}\text { Ip } 2 \\
\text { luous } \\
5.7 \% \text { ) }\end{array}$ & P value \\
\hline \multirow[t]{2}{*}{ Type of the used Patch } & Gortex & 69 & $90.8 \%$ & 60 & $93.8 \%$ & \multirow{2}{*}{0.517} \\
\hline & Bovine pericardial & 7 & $9.2 \%$ & 4 & $6.3 \%$ & \\
\hline \multirow{2}{*}{$\begin{array}{l}\text { The presence of } 2-3 \mathrm{~mm} \\
\text { significant residual }\end{array}$} & No & 67 & $88.2 \%$ & 56 & $87.5 \%$ & \multirow{2}{*}{0.905} \\
\hline & Yes & 9 & $11.8 \%$ & 8 & $12.5 \%$ & \\
\hline \multicolumn{2}{|c|}{ Cross clamp time (Minutes) (Median, Range) } & \multicolumn{2}{|c|}{$60.0(31.0-145.0)$} & \multicolumn{2}{|c|}{$60.0(20.0-187.0)$} & 0.659 \\
\hline \multicolumn{2}{|c|}{ CPB time (Minutes) (Median, Range) } & \multicolumn{2}{|c|}{$83.0(56.0-165.0)$} & \multicolumn{2}{|c|}{$84.5(40.0-226.0)$} & 0.498 \\
\hline \multicolumn{2}{|c|}{$\begin{array}{l}\text { Duration between the operation and the last } \\
\text { follow up (Months) (Median, Range) }\end{array}$} & \multicolumn{2}{|c|}{$12.0(2.0-90.0)$} & \multicolumn{2}{|c|}{$12.0(0.0-56.0)$} & 0.543 \\
\hline
\end{tabular}

CPB: cardiopulmonary bypass

Regarding the management and complications during intensive care unit admission; the frequency of prolonged ICU stay for more than 10 days was significantly higher in group 1 than in group 2 (Table 3 ). 
Table (3): Comparison between the studied groups regarding the management and complications during intensive care unit admission

\begin{tabular}{|c|c|c|c|c|}
\hline & & $\begin{array}{c}\text { Group 1 } \\
\text { Interrupted } \\
\mathrm{n}=67(54.3 \%)\end{array}$ & $\begin{array}{c}\text { Group } 2 \\
\text { Continuous } \\
\mathbf{n = 6 4}(\mathbf{4 5 . 7 \% )}\end{array}$ & $P$ value \\
\hline \multirow[t]{2}{*}{ Duration of ventilation (Days) } & Range & $1.0-9.0$ & $1.0-12.0$ & \multirow{2}{*}{0.082} \\
\hline & Median & 2.0 & 2.0 & \\
\hline \multirow[t]{2}{*}{ Duration of inotrope (Days) } & Range & $0.0-7.0$ & $0.0-12.0$ & \multirow{2}{*}{0.071} \\
\hline & Median & 2.0 & 1.0 & \\
\hline \multirow{2}{*}{$\begin{array}{l}\text { Heart block and the need for } \\
\text { PPM }\end{array}$} & No & $73(96.1 \%)$ & $60(93.8 \%)$ & \multirow{2}{*}{0.702} \\
\hline & Yes & $3(3.9 \%)$ & $4(6.3 \%)$ & \\
\hline \multirow[t]{2}{*}{ Duration of ICU stay (Days) } & Range & $2.0-15.0$ & $2.0-12.0$ & \multirow{2}{*}{0.208} \\
\hline & Median & 3.0 & 3.0 & \\
\hline \multirow[t]{2}{*}{ Length of ICU stay $>10$ days } & No & $61(80.3 \%)$ & $59(92.2 \%)$ & \multirow{2}{*}{$0.045^{*}$} \\
\hline & Yes & $15(19.7 \%)$ & $5(7.8 \%)$ & \\
\hline
\end{tabular}

PPM: permanent pacemaker; ICU: intensive care unit; *significant at $\mathrm{p}<0.05$

According to the findings of the last follow up echocardiography, there was no significant difference between the two groups as regard presence of clinically and sizable significant residual VSD and the need for second operation for permanent pacemaker insertion or the need for catheter or surgical VSD closure (Table 4).

Table (4): The frequency of VSD residual, and the need for second operation in the studied groups

\begin{tabular}{|c|c|c|c|c|c|}
\hline & & & $\begin{array}{c}\text { Group 1 } \\
\text { Interrupted } \\
\mathbf{n}=67(54.3 \%)\end{array}$ & $\begin{array}{c}\text { Group 2 } \\
\text { Continuous } \\
\mathbf{n}=\mathbf{6 4}(45.7 \%)\end{array}$ & P value \\
\hline \multirow{4}{*}{$\begin{array}{l}\text { The presence of } \\
\text { clinically and sizable } \\
\text { significant residual VSD }\end{array}$} & \multirow[t]{2}{*}{ No } & $\mathrm{N}$ & 72 & 62 & \multirow{4}{*}{0.688} \\
\hline & & $\%$ & $94.7 \%$ & $96.9 \%$ & \\
\hline & \multirow[t]{2}{*}{ Yes } & $\mathrm{N}$ & 4 & 2 & \\
\hline & & $\%$ & $5.3 \%$ & $3.1 \%$ & \\
\hline \multirow{4}{*}{$\begin{array}{l}\text { The need for second } \\
\text { unplanned operations }\end{array}$} & \multirow[t]{2}{*}{ No } & $\mathrm{N}$ & 73 & 58 & \multirow{4}{*}{0.301} \\
\hline & & $\%$ & $96.1 \%$ & $90.6 \%$ & \\
\hline & \multirow[t]{2}{*}{ Yes } & $\mathrm{N}$ & 3 & 6 & \\
\hline & & $\%$ & $3.9 \%$ & $9.4 \%$ & \\
\hline
\end{tabular}

VSD: ventricular septal defect

\section{DISCUSSION}

Open cardiac surgery is the definite treatment of the ventricular septal defects. It corrects the left to right shunt, prevents the development of pulmonary artery disease and aortic regurgitation, lowers the risk of infective endocarditis, and increases the long-term survival ${ }^{(10)}$.

This study compared the postoperative complication rates, and the outcomes of the interrupted and continuous suture techniques for surgical VSD closure. The study revealed comparable rates of heart block that needed PPM, postoperative clinically and sizable significant residual VSD, and the need for second unplanned operations, with no statistically significant differences.

Surgical VSD closure was performed by using interrupted sutures in $54.3 \%$, and by continuous sutures in $45.7 \%$ of the studied patients. Currently, there is no standardized suture technique for surgical
VSD closure, and the choice between them mainly depends on the surgical preference and experience.

The interrupted suture technique allows the surgeon to precisely visualize the size and the delineation of the defect and the related anatomic structures. On the other hand, continuous suture technique has the advantage of saving time, but it needs a solid understanding of the concepts of VSD closure and the detailed anatomic boundaries because of the obstructed view ${ }^{(9)}$.

In this study, the most commonly detected types of VSD were inlet (46.1\% versus $21.9 \%$ ), outlet (19.7\% versus $29.7 \%)$, and perimembranous (18.4\% versus $29.7 \%$ ), with significant difference between the studied groups. Different types of VSDs are known to result from failure of development or fusion of one of the membranous, muscular (trabecular), infundibular, atrioventricular or and the inlet parts of the interventricular septum (11). Perimembranous-type 
constitutes over $60 \%$ of VSDs, and approximately half requires repair. The repair of this type of ventricular septal defect carries the risk of interfering the, aortic and tricuspid valves and the conduction system ${ }^{(\mathbf{1 2})}$.

Goretex was the primary patch material used in both groups (90.8\% versus $93.8 \%$, respectively), otherwise, bovine pericardial type was used. There is no ideal patch material for VSD closure. Autologous pericardium has become the preferred material (13). However, successful use of Goretex patch for VSD closure has been reported ${ }^{(\mathbf{1 4})}$.

The presence of intraoperative $2-3 \mathrm{~mm}$ significant VSD residual was detected in in 9 patients in group 1 compared with 8 in group 2, with no significant difference. in this regard, Dodge-Khatami et al. ${ }^{(15)}$ concluded that residual defects after VSD repair almost always close, whereas one third remains open. Further, detection of a residual defect greater than $2 \mathrm{~mm}$ at initial repair on the cardiopulmonary bypass may obviate the need for second operation and life-long prophylactic antibiotics.

Concerning ICU management and outcomes of the studied patients, there were no significant differences between the interrupted and continuous suture techniques regarding the ICU care including the duration of mechanical ventilation and inotropes. Though patients belonged to group 1 showed significantly prolonged ICU stay than group 2 .

Complete heart block is a serious complication of VSD closure, which is associated with an increased risk of mortality ${ }^{(16)}$. In this study, the frequency of heart block that needed PPM was comparable in both groups (3.9\% versus $6.3 \%$, respectively). Similarly, Sen et al. ${ }^{(17)}$ did not find a statistically significant difference between the interrupted and continuous suturing techniques regarding the rates of atrioventricular block. Alternatively, GholampourDehaki et al. (18) recorded significantly higher incidence of conduction defects with continuous suture technique. Further, Anderson et al. ${ }^{(\mathbf{1 9})}$ have reported a very rare incidence (less than $1 \%$ ) of complete atrioventricular block in case series of VSD surgical closure. Anderson et al. ${ }^{(20)}$ have verified that VSD location and type of repair are important predictors for the risk of heart block. They reported that patients with atrioventricular canal repair were more likely to develop postoperative heart block compared to those with isolated VSD and trilogy of Fallot repair. The transition from tricuspid annulus to the muscular septum where the His bundle lies besides the careless suturing in this area can cause the heart block ${ }^{(9)}$. Advances in surgical techniques and to the attention to localize and avoid damage to the conduction pathway reduced the incidence of complete heart block ${ }^{\mathbf{1 1 7}}$

Long-term follow up echocardiography of the studied patient showed a comparable success rate of VSDs closure under both suture techniques. Four
(5.3\%) patients in group 1 compared with $2(3.1 \%)$ in group 2 had clinically and sizable significant VSD residual, with no significant differences. The residual VSD is usually related to insufficient intraoperative exposure with difficult identification of the transition from the tricuspid annulus to the conal septum superiorly ${ }^{(9)}$, or due to disruption of sutures with patch dehiscence ${ }^{(21)}$. In comparison to our finding, an earlier study compared interrupted and continuous sutures techniques in patients with trilogy of Fallot, and they found a significantly higher incidence of residual VSD with the continuous suturing than the interrupted ones (22). They also suggested that trabeculations decrease the full visualization of the whole extent of VSD. Furthermore, Gholampour-Dehaki et al. ${ }^{(18)}$ have detected a significantly higher incidence of residual shunt with continuous than interrupted sutures use.

\section{Strengths and Limitations:}

This study has the advantage of long-term follow up of the patients; however, it has some limitations including the retrospective design and the surgical procedures were performed by different surgical teams.

\section{CONCLUSIONS}

The present study indicates that interrupted and continuous VSD closure techniques have comparable success and postoperative complication rates. They demonstrated non-significant differences in the frequency of postoperative clinically and sizable significant residual VSD, the need for second unplanned operations, and heart block that needed permanent pace maker. Thus, the optimal suturing technique for VSD closure cannot be standardized, and their predilection depends on the experience and the comfort of the surgeons.

\section{REFERENCES}

1. Mostefa-Kara M, Houyel L, Bonnet D (2018): Anatomy of the ventricular septal defect in congenital heart defects: a random association? Orphanet Journal of Rare Diseases, 13: 118.

2. Hoffman J, Kaplan S (2002): The incidence of congenital heart disease. J Am Coll Cardiol., 39, 1890900.

3. Muscogiuri G, Suranyi P, Eid M et al. (2019): Pediatric cardiac MR imaging: Practical preoperative assessment. Magn Reson Imaging Clin N Am., 27: 243262.

4. Zhang J, Ko J, Guileyardo J et al. (2015): A review of spontaneous closure of ventricular septal defect. Proceedings (Baylor University. Medical Center), 28: 516-520.

5. Eroglu A, Atik S, Sengenc E et al. (2017): Evaluation of ventricular septal defect with special reference to the spontaneous closure rate, subaortic ridge, and aortic valve prolapse II. Pediatric Cardiology, 38: 915-921. 
6. Hopkins M, Goldstein S, Ward C et al. (2018): Evaluation and Management of Maternal Congenital Heart Disease: A Review. Obstet Gynecol Surv., 73: 116-124.

7. Yi K, You T, Ding Z et al. (2018): Comparison of transcatheter closure, mini-invasive closure, and openheart surgical repair for treatment of perimembranous ventricular septal defects in children: A PRISMAcompliant network meta-analysis of randomized and observational studies. Medicine, 97: 12583-12585.

8. Fraser C, Zhou X, Palepu S et al. (2018): Tricuspid valve detachment in ventricular septal defect closure does not impact valve function. The Annals of Thoracic Surgery, 106: 145-150.

9. Manning P (2018): Ventricular septal defect closure: How I teach it. The Annals of Thoracic Surgery, 106: 324-326.

10. Mirzaaghayan M, Moghadam E, Dehestani A et al. (2018): Early surgical closure of the ventricular septal defects; to be done or not to be done? A question to be answered. J Iranian Journal of Pediatrics, 28(6): 58876.

11. Lopez L, Houyel L, Colan $S$ et al. (2018): Classification of ventricular septal defects for the eleventh iteration of the international classification of diseases-striving for consensus: a report from the international society for nomenclature of paediatric and congenital heart disease. Ann Thorac Surg., 106: 15781589.

12. Santhanam $H$, Yang $L$, Chen $Z$ et al. (2018): A metaanalysis of transcatheter device closure of perimembranous ventricular septal defect. Int $\mathbf{J}$ Cardiol., 254: 75-83.

13. De Martino A, Milano A, Bortolotti U (2021): Use of Pericardium for Cardiac Reconstruction Procedures in Acquired Heart Diseases-A Comprehensive Review. Thorac Cardiovasc Surg., 69: 83-91.
14. Muthialu N, Balakrishnan S, Sundar R (2018): Single patch closure of multiple VSDs through right atrial approach. Indian Heart Journal, 70: 578-579.

15. Dodge-Khatami A, Knirsch W, Tomaske $M$ et al. (2007): Spontaneous closure of small residual ventricular septal defects after surgical repair. The Annals of Thoracic Surgery, 83: 902-905.

16. Andersen $H$, De Leval $M$, Tsang $V$ et al. (2006): Is complete heart block after surgical closure of ventricular septum defects still an issue? The Annals of Thoracic Surgery, 82: 948-956.

17. Sen O, Kadirogullari E, Aydin U et al. (2018): Comparison of continuous and interrupted suturing techniques in ventricular septal defect closure. Heart Surg Forum, 21: 418-422.

18. Gholampour-Dehaki M, Zareh A, Babaki S et al. (2016): Conduction disorders in continuous versus interrupted suturing technique in ventricular septal defect surgical repair. Research in Cardiovascular Medicine, 5: 28735-28735.

19. Anderson B, Stevens K, Nicolson $S$ et al. (2013): Contemporary outcomes of surgical ventricular septal defect closure. J Thorac Cardiovasc Surg., 145: 641-7.

20. Anderson J, Czosek R, Knilans T et al. (2012): Postoperative heart block in children with common forms of congenital heart disease: results from the KID Database. J Cardiovasc Electrophysiol., 23: 1349-54.

21. Zaman H, Cheema M, Jalal A (2000): The effect of residual ventricular septal defects on early clinical outcome: initial experience. J Coll Physicians Surg Pa., 10: $325-8$.

22. Tanveer R, Khan A, Siddiqi T et al. (2010): Continuous versus interrupted technique of ventricular septal defect (VSD) closure in total correction for tetralogy of Fallot pertaining to residual VSD. J Pak Med Assoc., 60: 253-6. 